\title{
Metaphor and Its Textual Functions
}

\author{
Xiaojing Yin \\ Shandong University of Finance and Economics, Shandong, 250014, China
}

\begin{abstract}
Metaphor is, in essence, mapping from the target domain to the source domain; from the familiar and concrete to the unfamiliar and abstract. When this happens, the entailments of metaphors as well as the contextual information will be integrated into texts and hence form coherent texts. Thus, it is accessible for us to explore discourse cohesion and coherence from the point view of conceptual metaphor. The present study is directed toward a comprehensive interpretation of how metaphors perform functions in the creation of discourse coherence and points out that metaphor is also a key mechanism for textuality. We finally come to the conclusion that conceptual metaphors facilitate discourse organization.
\end{abstract}

Index Terms - conceptual metaphor, cohesion, coherence, discourse organization

\section{INTRODUCTION}

The cognitive view on discourse analysis pays a lot of attention to the functional system and cognitive strategies for this linguistic unit. Language is thought to be the product of people's conceptualization of the objective world, and discourse, as a linguistic unit at a higher semantic level containing various individual semantic and syntactic forms, reflects the author's systematic cognition of certain objective phenomena, objects, events, etc. Therefore, understanding a discourse is closely related to the receiver's cognitive processing of the linguistic materials. When we receive a discourse, we are actually following the author's line of thought and carrying out a reasoning process to achieve successful communication with the author. Thus, we need to bridge the gap between the objective content in the discourse and the cognitive world in our minds. Such a process requires us to frequently refer to our knowledge and experience in mind, which constitutes our cognitive world, to give a complete interpretation of the discourse. With the close relationship between these two sets of concepts, we gain cohesion at the surface level as well as coherence achieved at the semantic level.

Ricoeur began to study metaphor at discourse level in his book The Rule of Metaphor published in 1975. He studies metaphor on basis of semantics that takes the word or the name as its basic unit. In his book, the progression from one discipline to the other corresponds to changes of the linguistic entity chosen for considerating settings: the word, the sentence and the discourse. But he never carries out a systematic research on authentic discourse. That is to say, he does not explore how metaphor works in discourse.

Later on, Gibbs explores the textual function of metaphor in his book The Poetics of Mind (1994). He claims that application of metaphors in a discourse contributes to the cohesiveness of text because metaphor works in a discourse by providing vivid context. (Goalty,1997, p.163) claims that "metaphor can be used, consciously or subliminally, to structure the development of a text, as the organizing principle which gives the text a lexical cohesion", which suggests that the study of metaphor has entered a new stage of research and application. At this stage, some scholars begin to notice the importance of analyzing metaphors at discourse level.

Cameron begins to consider metaphor from a textual and interactional perspective and published his insights on the textual function of metaphor in Metaphor in Educational Discourse (2002). She shows how different texts and interactional episodes may come not only with different types of metaphors, but also p63with different distribution patterns. She puts emphasis on conceptual metaphor used in classroom discourses and fails to explore how conceptual metaphors guarantees the cohesion of the discourse. Ponterotto (2003) argues that conceptual metaphor performs the cohesive function in discourses and conversations. His research focuses on conceptual metaphors behind the idioms and his study is to explore how the conversation strategies are related to conceptual representations and what determines the integration of knowledge during a rapid, complex exchange in a conversation. But his research focuses only on idioms, which limits his insights. Through the survey we find that attention is transferred into actual use of metaphors, topic extending and sentences organization. However, it is found that most research focuses on the ideational and interpersonal roles of metaphor. The chosen material is mainly confined in communicative contexts and literature texts. It is an urgent need to testify the theory in more rich materials. Based on former researches, this paper makes tentative research on discourse analysis in order to complete the original theory in depth and in detail.

\section{CONCEPTUAL Metaphor AND COHESION}

"Metaphor can be used, consciously or subliminally, to structure the development of a text, as the organizing principle which gives the text a lexical cohesion" (Goatly, 1997, p. 163). Metaphor is a cross-domain mapping from a source to a target. It is argued that extension of metaphor at discourse level is usually realized by analogical transfer, which maps metaphorical entailments from the source domain onto the target domain. Each mapping is a set of 
ontological correspondences across the two conceptual domains and metaphorical mappings preserve the cognitive topology of the source domain, in a way consistent with the inherent structure of the target domain (Lakoff \& Turner, 1989). Cohesive tokens are usually identified as grammatical connectors, logical connectors and lexical connectors. The most prominent cohesive evidence the conceptual metaphor embodies is lexis which, in most cases, contributes to a certain semantic category. They appear in clusters and chains.

\section{A. Identification of Metaphor}

We discuss first how to identify a metaphor from abundant conveyed messages. It should be mentioned that metaphor in the cognitive linguistic view means primarily conceptual metaphor, as opposed to linguistic metaphor (Kovecses, 2002). The present thesis adopts Steen's five-step procedure for metaphor identification as follows:

1. Identification of metaphor focus

2. Identification of metaphor idea

3. Identification of metaphor comparison

4. Identification of incomplete propositions

5. Identification of metaphor mapping

Step one: Identification of metaphorical focus

"Metaphorical focus" refers to the metaphorically used word as the focus that "stands out against the background of a literal frame" (Steen, 2002,p.394). "The focus is the linguistic expression used non-literally in the discourse" (Steen, 1999:61). Take the following sentence as an example:

(1) This is the journey we continue today. (Barack Obama's Inaugural Address Jan. 20th, 2009)

The above italicized word journey is the metaphorical focus. It means that the national life is like a journey. Therefore, the metaphorical focuses refer to something else analogous to a real journey.

Step two: Identification of metaphorical idea

"Metaphor identification is a matter of concepts, propositions, and reference... and propositional analysis was specially designed to cater for them...aims to bridge the gap between discourse and conceptualization" (Steen, 1999, p.64-65). Take the following sentence as an example:

(2) And we'll get our economy going again. And our best days are ahead of us.

The above italicized words like going and ahead of us show the metaphorical idea of economy as journey. There are no focuses as those in step one. The metaphors are implicit without explicit focuses. It shows that the progress of economy is like a forward movement of a journey. And the expression ahead of us shows that economic prosperity is the target or the destination of a journey.

Step three: Identification of metaphorical comparison

This step means to "set up the comparative structure that is implicit in the non-literal mapping between domains for every conceptual metaphor" (Steen, 1999, p.66).

(3) We've got to grow the economy from the bottom up. (The First Presidential debate)

The above italicized words grow and economy show that there are similarities between these two words in terms of one aspect of the characteristics of economy. Economic development can be referred to as the process of growing. Therefore, step three means to establish similarities between words.

Step four: Identification of the incomplete propositions

This step is to fill the incomplete propositions. It handles the reconstruction of the complete comparison statement by "inferring the implied concepts for the empty slots" (Steen, 1999, p. 68).

(4) But I know how to get America working again, restore our economy and take care of working Americans. (The 20th Presidential debate)

The incomplete proposition is "building", thus a metaphor is identified that ECONOMY IS BUILDING.

Step five: Identification of the metaphorical mapping

The last step is to "identify the complete non-literal mapping. This is done by filling out the conceptual structure of the two sides of the non-literal analogy, the source and the target domain" (Steen, 1999, p. 71-72).

(5) But I know how to get America working again, restore our economy and take care of building Americans. (The 20th Presidential debate)

In the above sentence, "building" corresponds to economy. The characteristics of building correspond to those of economy.

The above are the five steps of identifying metaphor. The first step of the present thesis is to work manually through literature word by word in search of metaphors according to Steen's five-step procedures.

\section{B. Conceptual Metaphor and Its Cohesive Functions}

Conceptual metaphors appear in sequence to form a variety of cohesive devices. Cohesion is created by metaphorical expression system which is governed by underlying systematic metaphorical concepts involving two domains and mappings between them. The following sections will explore how conceptual metaphor contributes to cohesion by presenting various cohesive devices produced by metaphorical expressions. According to the original classification given by Halliday and Hasan (1976), the relevant metaphorical cohesive devices are classified into three main types: reference, reiteration and collocation. 
Reference Constructed by Conceptual Metaphor

According to Halliday and Hasan (1976), only endophoric reference within the text makes cohesion. Endophoric reference consists of three types of reference: personal, demonstrative, and comparative. In English discourse, it is found that some words cannot be semantically interpreted in their own right. Instead, some information should be retrieved somewhere else. By referring to a metaphorical item in the text, it helps make a cohesive text. The following parts mainly focus on these three kinds of reference constructed by conceptual metaphor.

Personal Reference Constructed by Conceptual Metaphor

Personal reference involves the use of personals. The category of personals includes three kinds. The first one is personal pronouns, such as "he" "she" "it" and "they". The second is possessive pronouns, such as "his" "her" "its" and "their". The third is possessive determiners. These three kinds of personals represent reference of person.

(6) Marriage resembles a pair of shears, so joined that they cannot be separated; often moving in opposite directions, yet always punishing anyone who comes between them. (Sydney Smith)

It is clear that the whole sentence is linked by the conceptual metaphor MARRIAGE IS A PAIR OF SHEARS. Actually, the pronoun "they" refers to the source domain "shears" in the preceding clause. Cohesion lies in the continuity of reference. "Shears" is defined as a large cutting instrument shaped like scissors, used for shearing sheep, cutting hedges, etc., while "marriage" is a legal union between a man and a woman as husband and wife. At first glance, it is difficult to bridge "marriage" and "a pair of shears" together. However, the following clause explains the characteristics of "marriage". In this way, the mapping from "a pair of shears" to "marriage" is realized by their similarities.

Demonstrative Reference Constructed by Conceptual Metaphor

Demonstrative reference is reference by means of location, a scale of proximity. The speaker or writer identifies by employment of "this" "these" "here" or "now" if it is close, and "that" "those" "there" or "then" if it is in a location that is not close. (7) The Peterson's dog is the bane of the neighborhood. That bulldozer never stops digging.

The demonstrative pronoun "that" in the second sentence is used to make a thing specific, especially when it is seen as distant in space or time from the speaker or writer. And cohesion is constructed on the basis of the conceptual metaphor PETERSON'S DOG IS BULLDOZER. Peterson's dog serves as a target and bulldozer a source. In this case, "that", together with "bulldozer" obviously refers to "Peterson's dog" in the preceding sentence.

Comparative Reference Constructed by Conceptual Metaphor

Comparative reference is indirect reference by means of comparison. Two kinds of comparison are distinguished: general and particular "General comparison" means comparison simply in terms of likeness and unlikeness, without respect to any particular property, such as "same", "similar", "different" etc. On the other hand, "particular comparison" means comparison in a particular aspect of quantity or quality, including "More", "fewer", "better", "other", "otherwise", "else".

(8) Some books are to be tasted, others to be swallowed, and some few to be chewed and digested. (Francis Bacon, Of Studies)

In this passage, comparative reference is realized by the use of "others" and "few". It is easy to find out the implicit conceptual metaphor BOOKS ARE FOOD, whose metaphorical meaning is revealed by verbs like "tasted, swallowed, chewed and digested". In this metaphor, the characteristics of "food" are first mapped onto the "books" and then the characteristics of "eating food" are mapped onto "reading books". Both "others" and "few" refer to "books" through this mapping and it forms a coherent passage.

Reiteration Constructed by Conceptual Metaphor

As one kind of lexical cohesion, reiteration is broadly used to create cohesion in discourse. Reiteration is realized through repetition. Three types of repetition are discussed in the following section, including identical words, synonyms or near synonyms, super-ordinate or general word.

Identical Word

The use of identical word is the most direct form of repetition which forms lexical cohesion. Look at the following example:

(9) Above me towered the colossal edifice of society and to my mind the only way out was up. Into this early resolved to climb. Up above, men wore black clothes and boiled shirts, and women dressed in beautiful gowns... (Jack London, What Life Means to Me)

In this example, "society" is compared to "colossal edifice" with "society" as a target and "edifice" as a source. The term "edifice" is repeated and achieves cohesion in this text. In the extension process, there exists a crossing mapping from the concrete to the abstract. "Up", "climb" and "up above" used in the following sentences all illustrate the nature of "edifice". "Society" is rigidly stratified by social status, at the top of which is the upper-class, while the lower-class is at the bottom. In this sense, the common ground between "society" and "edifice" is that both of them are arranged in order of height. Then the two originally separated domains are connected by this mapping.

Synonyms or Near Synonyms

It is more frequent to find the use of a set of similar or approximate words or phrases to modify the same target domain:

(10) Smiles are passports through the desert... visas to all alien countries. 
In the above example, metaphors involve one target domain and two source domains. Thus, two conceptual metaphors are produced SMILES ARE PASSPORTS and SMILES ARE VISAS. Based on our general knowledge, passport refers to an official document issued by a government, identifying an individual, granting him permission to travel abroad, and requesting the protection of other governments for him. Visa is an official authorization appended to a passport, permitting entry into and travel within a particular country or region. Therefore, "passport" and "visa" are similar in that both of them guarantee that the holder can travel in foreign countries. The common characteristics of the two concepts are mapped onto "smiles" by analogy. In this way, "passport" and "visa" are used to make it salient that "smiles" can work well everywhere, thus giving the reader a vivid description of what "smiles" sounds like. This kind of metaphor is of great importance in organizing a text.

Super-ordinate Word or General Word

In addition to "identical words" or "similar words", super-ordinate words can act as a tree and categorize the different domains into one category at different levels, thus making the whole discourse cohesive:

(11)I once have said that, my attachment, can be said of many intimate relations, with mainland my mother, Taiwan my wife, while Hongkong a sweetheart and Europe my love ( Guangzhong Yu).

In this example, four metaphors coexist: MAINLAND IS MOTHER; TAIWAN IS WIFE; HONGKONG IS SWEET HEART, and EUROPE IS EXTRAMARITAL LOVE. "female" can be taken as a super-ordinate word, while "mother," "wife", "sweetheart" and "extramarital love" are subordinate words. In cognitive linguistics, this mental process of classification is called categorization. Usually, there are three levels of categories, that is, basic level category, subordinate category and super-ordinate category. The super-ordinate level performs a collecting function grouping together categories that are closely linked in our knowledge representation system, while the subordinate fulfils a specific function. Here, "mother," "wife", "sweetheart" and "extramarital love" are at the subordinate level, while "female" is at the super-ordinate level. In this way, the cohesive chain can be achieved by using a set of words guided by a super-ordinate word or a general word. It should be made clear that the super-ordinate word "female" here also can be considered as a "general word".

Collocation Constructed by Conceptual Metaphor

Collocation as a subclass of lexical cohesion involves a pair of lexical items that are associated with each other in the language. To be brief, collocation is a tendency to co-occur:

(12) Boomerangs were like relationships. You got the process. The boomerang decided what you put in and never had complete control would return and some days, if the conditions were bad, it would never come back. Selecting a suitable boomerang for the conditions helped but not always. (Mark Hansen, Boomerangs)

"Boomerang" is a flat wooden missile which can be thrown so that it returns to the thrower if it fails to hit anything. The common ground between "boomerang" and "relationship" is explained by the following sentences---the more you give, the more you will get. In this example, "out" and "in" are used to form a kind of opposite collocation. In fact, "relationship" indicates a spatial metaphor. There is an internal systematicity to each spatial metaphor. Spatial metaphors are rooted in physical and cultural experience. They are not randomly assigned. "Out" and "in" give orientations, which are coherent with spatial cases. Therefore, "out" and "in" define a cohesive system rather than a number of isolated and random cases.

Conceptual Metaphor and Coherence

\section{CONCEPTUAl Metaphor And Discourse COHEREnCE}

As mentioned before, conceptual metaphor is a thinking pattern having its own entailments and cognitive characters. All these entailments in a conceptual metaphor form an entailment ground, on which coherent ideas and sub-concepts are generated and organized. We hold that there are four kinds of entailments at discourse level: intra-metaphorical entailment, inter-metaphorical entailment, parallel entailment and hierarchical metaphorical entailment.

\section{A. Intra-metaphorical Entailment and Coherence}

We can find a coherent discourse that involves only one conceptual metaphor. In this case, the target concept reflects the metaphorical entailments of the source concept and we get to touch the target domain in terms of the source domain woven coherently and systematically. For example:

(13) Time is treated as if it were something almost tangible. We budget it, save it, waste it, steal it, kill it, cut it, account for it; we also charge for it. (A. Lamer, Go-Go Americans)

In this example, there is a conceptual metaphor TIME IS TANGIBLE OBJECT, in which TIME is the target domain and TANGIBLE OBJECT is the source domain. We comprehend time, an abstract concept, in terms of a tangible object which can be disposed of at our will. These metaphorical entailments can be invoked to help us understand TIME in terms of the metaphorical TIME CAN BE DISPOSED OF AT WILL. By means of the conceptual metaphor TIME IS TANGIBLE OBJECT, the discourse progresses as a coherent one.

One conceptual metaphor can achieve not only the coherence of itself, but also the coherence of text in which it exists. Look at the following example:

(14) Entomologists tell us of a strain of ants known to science as the sanguinea---a species so martial and imperialist in disposition that they are commonly referred to as army ants, or soldiers. In the insect world, their inroads may well be 
dreaded, as once the declined advent of the Roman was a signal of alarm to lesser peoples. For not only do they make war, they are also, it appears, slave owners who prey on unfortunate neighborhood colonies such as those of the wood ants. When a slaving expedition is mounted; the attacking of sanguinea divides into columns, each led by a scout, approaching the hostile fortress from different directions. Once in sight of their objective they call a halt. Then, while the other detachments maintain a blockade, one unit is sent forward as an assault force. As a rule these invaders easily beat down whatever resistance is offered to them. The wood ant defenders attempt to evacuate their positions; bearing with them the cocoons of their blood, but their line of retreat is cut off by the besiegers, who capture the fugitives while the storm troops continue to scour the fortification (Goatly, 1998, p.163).

This text is concerned with a kind of ant named sanguinea, and one conceptual metaphor runs through the whole text, that is, SANGUINEA IS ARMY. Here ARMY is used to give a vivid description of SANGUINEA, and we get to know the characteristics of ants in terms of soldiers. On mapping between the two domains, many words about army or soldiers are used. Some are nouns, for example, "disposition", "inroads", "scout" and "fortress"; some are verbs, such as "evacuate", "capture" and some others are objectives: "martial", "imperialist", "dreaded", "disciplined", "hostile", etc. They are all military words used to describe war and soldiers. In other words, these words are the entailments of ARMY. Conceptual metaphor is a mapping process from the source domain to the target domain, so these entailments of ARMY is mapped onto the target concept SANGUINEA. For example, "martial and imperialist" correspond to the "dreaded feature of sanguinea", "a slaving expedition" corresponds to "an attack on wood ants", "neighborhood colonies" correspond to "other ants' nests surrounding" "invaders" correspond to "sanguinea who attack the wood ants". We list them in the following figure, mappings in SANGUINEA IS ARMY.

Source Domain: A RMY

martial and imperialist

a slaving expedition

neighborhood colonies

invaders

\section{Target Domain: SANGUIMEA}

dreaded feature of sanguines

an attack on wood ants

other ants 'nests surrounding sanguinea

sanguinea who attack the wood ants these sentences and treat the text as a coherent whole. From the above analysis, we know how one conceptual metaphor achieves coherence in a text. Words used to describe the source domain in a text constitute the entailments of the source domain, and then these entailments are mapped onto the target domain which is then added with these new entailments. Therefore, sentences containing these words are coherent correspondingly to ensure a whole coherent text.

Thus, one conceptual metaphor constructs a discourse at the macrostructure level. The notion of macrostructure has been introduced by van Dijk (1977) to provide an abstract semantic description of the global content of discourse. It refers to the main idea or topic of a discourse. Conceptual metaphor has its framing function for the sequence of a discourse and the whole discourse develops accordingly. Let us consider another example:

(15) The chess-board is the world: the pieces are the phenomena of the universe; the rules of the game are what we call the laws of nature. The player on the other side is hidden from us. We know his play is always fair, just and patient. But also we know, to our cost, that he never overlooks a mistake, or makes the smallest allowance for ignorance. (Thomas Henry Huxley)

In this example, the initial metaphor is WORLD IS CHESS-BOARD which acts as a frame in the whole paragraph. Under this framework, "the phenomena of the universe" are compared to "the pieces", "the laws of nature" to "the rules of the game" and "the nature" is compared to "the player". The conceptual domain of CHESS-BOARD is systematically mapped onto that of WORLD, and the metaphorical entailments of the source domain help us constructing the target domain WORLD. There exists a lexical cohesive chain which connects the whole discourse tightly and helps to make the discourse coherent.

\section{B. Inter-metaphorical Entailment and Coherence}

In some discourses, there is a type of metaphorical expression with overlapping entailments building a common ground to achieve coherence. That is, there is no central conceptual metaphor, but several parallel conceptual metaphors functioning equally. These different conceptual metaphors usually have a shared metaphorical entailment that can make a discourse develop in a coherent way. Two situations for texts of this kind usually exist. One is a central conceptual metaphor out of which a series of sub-conceptual metaphors are generated; and the other is the presence of several parallel conceptual metaphors working together. Let us take several examples to illustrate this point:

(16) Chao Xinmei was already in her highness and mighty, when she heard from Miss Su that Hung-chien indeed returned home in the same ship together with her, her face turned pale as if Hung-chien had turned into thin air, expressionless. If Miss Su had not spoken to him, Hung-chien would think that his presence was as dark as absence, just like a phantom of early dawn upon the cock's crowing or the Taoist truth that it can be felt but not be seen, can be expounded but can not be touched.(Weicheng, 2003, p.52)

The example shows that a series of metaphorical expressions are produced systematically which ensures internal discourse coherence. Hung-chien is neglected or ignored by others. Chao acted as if Hung-chien had turned into thin air and Hung-chien himself felt he was just like a phantom of early dawn upon the cock's crowing or the Taoist truth, which can be "felt but not seen, expounded but not touched". Source domains like "the thin air", "phantom" and "the Taoist truth" share some entailments. For "the thin air", we have the entailments such as "colorlessness", 
"invisibleness". "phantom" is an imaginary term suggesting gods which are invisible to people. As to "the Taoist truth", it is abstract and we can not easily comprehend it. For these three source domains, the common entailment is "invisibleness" and that is to say, "invisibleness" is the overlapping entailment between the different domains. They together provide a vivid description of how Hung-chien is neglected and looked down upon by Chao. It is the overlapping entailment that makes the metaphorical description a coherent one. All the following metaphorical expressions serve this topic and the entailments inferred from the different domains are also related to the topic. In other words, the topic helps readers to determine the choice of entailments from each domain, since there are a large number of entailments that can be inferred. Look at another example:

(17) If those department stores that are decorated with colorful Christmas lights are full of French flavor, then the small markets scattered throughout Paris are refreshments for appetizers on a feast. Though the feast may be intoxicating, yet the refreshments give us deeper impression. (Reader's digest V11, p.52)

This text gives a vivid description of department stores and small markets in Paris. There are two conceptual metaphors in the text, namely, DEPARTMENT STORES ARE FEASTS and MARKETS ARE REFRESHMENTS. The two conceptual metaphors share neither the same target domain nor the same source domain. That is to say, two different source domains FEASTS and REFRESHMENTS employed to describe two different target concepts DEPARTMENT STORES and MARKETS. The two conceptual metaphors function equally in this text and constitute a parallel structure. All metaphorical expressions derive from the two conceptual metaphors, and the coherence of the two conceptual metaphors help achieve textual coherence. Feasts are attractive and few people can refuse them, and in department stores we can not help buying attractive goods. The two domains in each conceptual metaphor generate systematic correspondences. We will find that DEPARTMENT STORES and MARKETS, FEASTS and REFRESHMENTS are comparable. And the comparison serves as the base for coherence of the two conceptual metaphors as well as the whole text.

Another way is through one presupposed conceptual metaphor and two explicit ones to construct the coherence of text. Let us look at an example taken from (Shu Dingfang2000, p. 82):

(18) Man of virtue is water and man of wickedness is oil. After many years of cooking and getting in touch with different people, I find they share something in common. Water, is clear, cool and easy to evaporate; while held for a $\operatorname{sip}$, it is tasteless. Wherever there is water, there is freshness. When water meets oil, it will become turbid, but will not splash. Thus water can be used to describe a gentleman. However, the oil without any transparency, is strongly adhesive, full of creamy. A drip of oil may render dust adhered to it. The oil cannot be invaded by a drop of water for it never surrenders to a drop of water. Thus oil can be said of a villain.

We have no difficulty in recognizing two explicit conceptual metaphors: MAN OF VIRTUE IS WATER, and MAN OF WICKEDNESS IS OIL with MAN OF VIRTUE and MAN OF WICKEDNESS as target domains and WATER and OIL as source domains respectively. All sentences derive from these two conceptual metaphors and the whole text is organized on the basis of them. We comprehend MAN OF VIRTUE in terms of its property of limpidness in contrast with dirty things which corresponds to goodness of a man. In MAN OF WICKEDNESS IS OIL metaphor, the target concept MAN OF WICKEDNESS is interpreted in terms of the source concept OIL. For oil is turbid and dirty. The same characteristics can be said of men of wickedness, who are dishonest and wily. Firstly, through a comparison between the two target domains MAN OF VIRTUE and MAN OF WICKEDNESS, we will find that the former is positive while the latter negative. They form a hierarchical system, with human beings at the superior level and man of virtue and man of wickedness at inferior level. Oil and liquid form a hierarchical structure, with liquid at higher level while water and oil at lower level. We can find that an implicit and presupposed conceptual metaphor underlies the text: HUMAN BEING IS LIQUID, which governs these two explicit conceptual metaphors MAN OF VIRTUE IS WATER and MAN OF WICKEDNESS IS OIL. They form a systematic structure with HUMAN BEING IS LIQUID at higher level, which ensures coherence in this text, as well as the three conceptual metaphors. In a word, the three conceptual metaphors, one is presupposed and the other two explicit, are coherent with each other. Therefore, the whole text is organized coherently. Another example is given below:

(19) These passions, like great winds, have blown me hither and thither, in a wayward course, over a deep ocean of anguish, reaching to the very verge of despair. (Bertrand Russell, What I Have Lived For)

There are three metaphors in this discourse: these passions are great winds; anguish is a deep ocean; and despair is a container with verge. The first one is the central metaphor, for it provides orientation for the whole passage and brings out the latter two, while the latter two sub-metaphors form a metaphorical structure themselves and meanwhile facilitate the formation of the central metaphor. If a discourse contains more than one metaphor, but they do not develop a central proposition, then this discourse is not concentrated on a unified topic, and is therefore not coherent.

\section{Parallel Metaphorical Entailment and Coherence}

Metaphor can organize a discourse by parallel progressive mapping. It may involve the progressive development of several correlated conceptual metaphors. Through interaction across different domains, the discourse develops in a coherent way. Let us look at the conceptual following examples:

(20) Life is like a pot of tea. The head round tastes with great fragrance that is like a person's early year's of life. The body one, is the enterprising young man, full of energy but still with ups and downs. It tastes full-bodied flavor. 
Tea, after several rounds, becomes tasteless and with a tint of both sweet and bitter, which assembles a man entering his old age and returns to his nature of being simple.

In the above example, the metaphor, LIFE IS TEA, acts as a frame for the whole passage. Through this conceptual metaphor, the source domain TEA is mapped onto the target domain LIFE. This mapping controls the following three mappings. Then the discourse develops in a parallel progressive way concerning several analogical aspects of the source domain and the target domain. We can say that the mappings make the different conceptual domains interact with each other and thus keep the discourse coherent.

Text coherence can also be achieved through several parallel conceptual metaphors. In a text of this kind, conceptual metaphors make equal contribution to coherence and they form a parallel structure:

(21) The Middle-aged is a bus, though may be not a brand one, with its windows shattered off and seats torn down, is still very popular for its high capacity. The bus keeps on the move till it arrives at its destination. On the contrary, the brand ones, such as Lincoln, Cadillac serve just one single person. Only, buses are also in trouble when it brakes down on the anchor, which is a common occurrence. The middle-aged is an overdue ticket, whether can be accepted to board or not depends on the captain. He has to wait and see if there is a sixpenny seat to accommodate him. The middle-aged has nothing to offer for he has no good appearance, profession or energy. They are the most likely to be laid off. The middle-aged is a soccer match with half an hour left before it concludes. Before the match they are supposed to kick two goals. Yet it disappoints all that it scores zero and The World Cup is completely hopeless. It also seems that no great progress will be made in the next half round.

There are three conceptual metaphors in this text, namely, MIDDLE-AGED MAN IS BUS, MIDDLE-AGED MAN IS OVERDUE SHIP TICKET and MIDDLE-AGED MAN IS HALF-ENDED SOCCER MATCH. The text is constructed on the basis of these conceptual metaphors. Let us first analyze MIDDLE-AGED MAN IS BUS. Many people take bus as their vehicles when go out. Buses not kept in good condition are prone to break down. These features of bus correspond to those of a middle-aged man: having rich experiences but very likely to get ill. The second conceptual metaphor is MIDDLE-AGED MAN IS OVERDUE SHIP TICKET. With economic reforms in the 1990s, a lot of middle-aged people fail to meet new demands brought about by new challenges and became laid-off workers. This corresponds to the feature of the concept "overdue ship ticket": being invalid. The third conceptual metaphor is MIDDLE-AGED MAN IS HALF-ENDED SOCCER MATCH. When a soccer match is about to conclude, there will be scarce chances for players to score a goal. For middle-aged people who have not yet get any achievement, life will be even harder. So we see that these two domains correspond with each other. All expressions in this text derive from the three conceptual metaphors respectively, so their coherence is dependent on the coherence of the three conceptual metaphors. And we can see that the three conceptual metaphors share the same target domain MIDDLE-AGED MAN, thus forming a parallel structure. They are coherent on basis of their overlapping entailment: the three source domains are used to highlight three different aspects of the same concept MIDDLE-AGED MAN. Therefore, the metaphorical expressions in the text are coherent; and consequently the whole text is coherently constructed.

\section{Hierarchical Metaphorical Entailment and Coherence}

Different conceptual metaphors may systematically relate with each other and form a hierarchical structure. In this case, there is usually a basic conceptual metaphor according to which a series of sub-conceptual metaphors are generated. The basic metaphor acts as a frame for the whole discourse and restricts the sub-conceptual metaphors. For instance:

(22) All the world's a stage,

And all the men and women merely players.

They have their exits and their entrances;

And one man in his life plays many parts.

His acts being seven ages.

At first, the infant. . .

(William Shakespeare, As You Like It, 2.7)

From this famous passage from Shakespeare's As You Like It, we know that there is a basic metaphor LIFE IS PLAY with LIFE being a target and PLAY a source. It is well-known that a play consists of many elements, such as, players, costume, stage, audience, directors, roles, exits or entrances of players. In the narrow sense, life held by an individual is conceptualized as a play. The constituent elements in the domain of life, such as, the involved person, his birth, his death, etc. are mapped systematically to the source domain play, such as the actor, beginning and ending of the play, etc. To be more precise, the play corresponds to life, the actor or actress to the person leading a life ahead, and his performance to his life quality. Furthermore, the beginning of a play is conceived of as the birth of a person, the climax of the play normally as a satisfying state of his life while the last scene or the falling of the curtain indicating end of the play as the moment of his death. In a given situation, the moment when an actor enters or exit from the stage can also be conceived of the birth and death of a certain person. On the stage, the actor may play different roles in a play, which corresponds to that a person may undertake different responsibilities during his lifespan, that is, he may simultaneously be a lovely father as regards to the child, an obedient son to the parents and a responsible husband to the wife. If the person leads a happy life with satisfying social relations and achievements, his life can be assumed as a comedy with a 
happy ending; if the person goes through many failures and frustrations and has a miserable end, his life can be commented as a tragedy.

With this metaphor, several sub-conceptual metaphors are generated: WORLD IS STAGE, MEN AND WOMEN ARE PLAYERS, BIRTH OF PEOPLE IS ENTRANCE OF PLAYERS, DEATH OF PEOPLE IS EXIT OF PLAYERS. The conceptual metaphor LIFE IS A PLAY goes through the whole discourse. It activates the sub-conceptual metaphors which form a hierarchical entailment system. These sub-conceptual metaphors serve as the constituting parts of the basic metaphor and help to construct a unified and coherent discourse. Let us take another example:

(23) Some books are to be tasted, others to be swallowed, and some few to be chewed and digested; that is, some books are to be read only in parts; others to be read, but not curiously; and some few to be read wholly, and with diligence and attention. (Francis Bacon, Of Studies)

In (24), we can easily identify a basic metaphor IDEAS ARE FOOD though the source domain FOOD does not appear in this discourse. Bacon first illustrates some characteristics of eating food through verbs like "taste, swallow, chew and digest". Then these characteristics are mapped onto reading books. Thus we can comprehend the concept BOOKS, or IDEAS in terms of the concept FOOD through the following mappings:

$\begin{array}{lc}\text { Source Domain } & \text { Target Domain } \\ \text { FOOD } & \text { BOOKS; IDEAS } \\ \text { To taste } & \text { to read in parts } \\ \text { To swallow } & \text { to read without curiosity } \\ \text { To chew and digest } & \text { to read wholly }\end{array}$

These mappings can also be laid out as conceptual metaphors that provide the submappings of the IDEAS ARE FOOD metaphor:

\section{THINKING IS COOKING}

\section{ACCEPTING IS SWALLOWING}

CONSIDERING IS CHEWING

\section{UNDERSTANDING IS DIGESTING}

We cook food and we can stew over ideas. We swallow food and we can swallow a claim or insult. We chew food and we can chew over some suggestion. We digest food and we can or can not digest an idea. We get nourishment from eating food and we are nourished by ideas. These similarities can be laid out as perceived structural similarities between the concepts of food and ideas. While reading it, the reader can easily apply different actions of eating food to comprehend various ways of reading books. These mappings correlate with each other by these conceptual domains. So the conceptual metaphor BOOKS ARE FOOD links the whole passage tightly and maintains coherence in this discourse.

\section{DISCUSSION}

Conceptual metaphor theories provide us with a foothold from which people can observe the internal structure of a discourse. Because conceptual metaphor plays an important role in the expression of human experiences, we assume that it can be a cohesive force in discourse. The purpose of this thesis is to apply insights from the contemporary theory of conceptual metaphor to the analysis of cohesive and coherent functions of conceptual metaphor in discourse studies. To summarize, the cohesive chains of conceptual metaphor can be created by reference, reiteration as well as collocation. The cohesive chains realized by reference are formed by personal reference, demonstrative reference and comparative reference. Reiteration is created by repeating the identical word, synonyms or near synonyms or utilizing a super-ordinate or a general word. In this sense, conceptual metaphor serves as a cohesive device at the surface level of discourse.

\section{REFERENCES}

[1] Black, M. (1993). More about Metaphor: Metaphor and Thought. Ed. Ortony, A. Cambridge: Cambridge University Press.

[2] Cameron L. \& Low, Q. (2001). Researching and Applying Metaphor. Shanghai: Shanghai Foreign Language education Press.

[3] Cameron, J. (2002). Metaphor in Educational Discourse. London \& New York: Continuum Press.

[4] Diane, P. (2000). The Cohesive Role of Cognitive Metaphor in Discourse and Conversation. Berlin: Mouton De Gruyter.

[5] Gibbs, R. W. and G. J. Stern. (1999). Metaphor in Cognitive Linguistics. Amsterdam: John Benjamins Publishing Company.

[6] Goatly, A. (2000). Critical Reading and Writing. London and New York: Routledge.

[7] Halliday, M. A. K. (2000). An Introduction to Functional Grammar. Beijing: Foreign Language Teaching and Research Press.

[8] Hoey, M. (1991). Patterns of Lexis in Text. Oxford: Oxford University Press.

[9] Kovecses, Zoltan. (2002). Metaphor: A Practical Introduction. New York: Oxford University Press.

[10] Lakoff, G. \& M. Johnson. (1980). Metaphors We Live By. Chicago: The University of Chicago Press.

[11] Lakoff, G. (1987). Women, Fire and Dangerous Things. Chicago: The University of Chicago Press.

[12] Lakoff, G. (1993). The Contemporary Theory of Metaphor: Metaphor and Thought. Cambridge: Cambridge University.

[13] Langacker, R. W. (2004). Foundations of Cognitive Grammar. Beijing: Beijing University Press.

[14] Ponterotto, D. (2003). The cohesive role of cognitive metaphor in discourse and conversation. Berlin and New York: Mouton de Gruyer.

[15] Ricoeur, P. (1986). The Rule of Metaphor. London: Routledge and Kegan Paul. 
[16] Santa Ana, O. Brown. (2002). Tide Rising: Metaphors of Latins in Contemporary American Public Discourse. Austin, TX: University of Texas Press.

[17] Steen,G. (1994) .Understanding Metaphor in Literature: An Empirical Approach. New York: Longman.

[18] Stern, J. (2000). Metaphor in Context. Cambridge, Mass: MTT Press.

[19] Taylor, J. R. (2002). Cognitive Grammar. Oxford: Oxford University Press.

[20] van Dijk, T. A. (1997). Discourse as Structure and Process. London: SAGE Publications.

[21] Ungerer, F. \& Schimid, H. J. (2001). An Introduction to Cognitive Linguistics. Beijing: Foreign Language Teaching and Research Press.

[22] Zhengkun Gu. (2007). Tao and Teh. Beijing: China publications Co. Ltd.

Xiaojing Yin, a College English teacher for English major students in Shandong University of Finance and Economics in Jinan, has been teaching college English for ten years. During this decade, she published several papers and translated two piece works of American literature. Her research field is linguistics. 